\title{
EXTRAÇÃO DE ÓLEO ESSENCIAL E COMPOSTOS FENÓLICOS DO LIMÃO TAITI (CITRUS LATIFOLIA) USANDO CO2 E LÍQUIDOS PRESSURIZADOS.
}

\author{
Talita Yuri Yamada Araújo*, Francisco Manuel Barrales e Julian Martínez.
}

\section{Resumo}

O Brasil tem destaque no cenário mundial por ser um grande produtor de frutos cítricos, sendo um deles o limão Taiti. $\mathrm{Na}$ produção de suco desse fruto, ocorre a geração de vários subprodutos, como casca e bagaço. A casca, em especial, apresenta alto conteúdo de compostos fenólicos com caráter antioxidante. Foi realizado um estudo sobre a extração dos compostos fenólicos do limão Taiti por meio da técnica de extração com líquidos pressurizados (PLE Pressurized Liquid Extraction), sob diferentes temperaturas e utilizando etanol e água como solventes. Através do monitoramento de variáveis como temperatura, pressão e concentração de solventes, foi possível avaliar que a melhor condição experimental foi a extração na temperatura de $75 \stackrel{\circ}{ } \mathrm{C}$, com a utilização de solvente de $75 \%$ de etanol em água.

\section{Palavras-chave:}

Subproduto, Composto fenólicos, Antioxidantes.

\section{Introdução}

A casca do limão Taiti apresenta um alto conteúdo de compostos fenólicos, que possuem capacidade antioxidante. Para avaliar o uso desses compostos antioxidantes, foi utilizada a técnica de extração com líquidos pressurizados (PLE), que apresenta a vantagem de ser um método rápido, permitindo a utilização de solventes não tóxicos, como etanol e água, em temperaturas moderadas ou altas.

Portanto, o objetivo desse projeto foi determinar as melhores condições para a extração de compostos fenólicos da casca do limão Taiti por PLE, avaliando extrações em diferentes temperaturas e com a utilização de solventes com diferentes concentrações de etanol.

\section{Resultados e Discussão}

A casca de limão seca foi triturada e armazenada em embalagens herméticas, a $-18 \stackrel{\circ}{\circ}$, na ausência de luz. Para cada experimento, utilizou-se $2 \mathrm{~g}$ de massa de material. O tempo de extração foi de $40 \mathrm{~min}$ e a pressão foi mantida em $10 \pm 2 \mathrm{MPa}$, com vazão mássica de solvente constante. As temperaturas utilizadas foram 50 , 75 e $100 \stackrel{\circ}{\circ}$, e as concentrações de etanol dos solventes foram 50,75 e $100 \%(\mathrm{~m} / \mathrm{m})$,

A determinação do teor de compostos fenólicos dos extratos foi realizada pelo método de Folin-Ciocalteu. A capacidade antioxidante foi avaliada pelos métodos de capacidade de absorção de radicais de oxigênio (ORAC) e de capacidade de redução de ferro (FRAP).

A Tabela 1 apresenta os resultados das extrações nas condições experimentais estabelecidas.

Tabela 1. Rendimento global, teor de fenólicos totais e capacidade antioxidante dos extratos.

\begin{tabular}{cccccc}
\multicolumn{2}{c}{ Condição experimental } & Rendimento(\%) & $\begin{array}{c}\text { Fenólicos } \\
\text { (mgGAElgCS) }\end{array}$ & $\begin{array}{c}\text { FRAP } \\
\text { (mgTx/gCS) }\end{array}$ & $\begin{array}{c}\text { ORAC } \\
\text { (mgTx/gCS) }\end{array}$ \\
\hline \multirow{2}{*}{100} & 50 & $1,406 \pm 1,161$ & $0,9646 \pm 0,268$ & $3,6993 \pm 1,727$ & $19,0159 \pm 6,217$ \\
& 75 & $4,315 \pm 1,373$ & $2,0342 \pm 0,126$ & $6,94 \pm 0,26$ & $58,6644 \pm 8,367$ \\
& 100 & $7,3724 \pm 1,935$ & $2,6284 \pm 0,118$ & $9,5152 \pm 0,527$ & $73,0254 \pm 10,300$ \\
\hline \multirow{2}{*}{75} & 50 & $4,462 \pm 0,239$ & $1,6372 \pm 0,113$ & $5,1939 \pm 0,339$ & $69,5881 \pm 28,110$ \\
& 75 & $8,234 \pm 0,589$ & $2,6713 \pm 0,294$ & $6,3411 \pm 0,455$ & $80,9049 \pm 8,288$ \\
& 100 & $11,4935 \pm 1,2308$ & $3,0024 \pm 0,390$ & $8,0747 \pm 0,294$ & $65,7382 \pm 4,276$ \\
\hline \multirow{2}{*}{50} & 50 & $4,889 \pm 0,194$ & $2,0778 \pm 0,113$ & $6,1547 \pm 0,600$ & $79,9949 \pm 17,644$ \\
& 75 & $8,658 \pm 0,206$ & $2,6748 \pm 0,311$ & $5,5600 \pm 0,202$ & $90,1023 \pm 22,731$ \\
& 100 & $1,8005 \pm 0,4222$ & $0,7718 \pm 0,153$ & $2,2004 \pm 0,677$ & $23,6649 \pm 1,801$ \\
\hline
\end{tabular}

O rendimento global aumentou com a temperatura, pois quando o solvente pressurizado é aquecido, a sua viscosidade diminui e as ligações moleculares entre os compostos extraíveis e a matriz vegetal enfraquecem. Assim, ocorre uma melhor penetração do solvente na matriz vegetal, contribuindo com 0 aumento de concentração de compostos fenólicos de caráter antioxidante nos extratos.

$A$ adição de água ao etanol também contribuiu para o aumento do rendimento global dos extratos, pois ela altera a polaridade e a densidade do solvente, elevando a capacidade do solvente de extrair compostos com maior polaridade.

Os melhores resultados para o teor de fenólicos e a capacidade antioxidante foram obtidos com a utilização de solventes com 75 e $50 \%$ de etanol, na temperatura de 75 C. Portanto, a melhor condição experimental deu-se na temperatura de $75^{\circ} \mathrm{C}$ com a utilização de solvente com $75 \%$ de concentração de etanol em água.

\section{Conclusões}

A elevação da temperatura contribui para o aumento do rendimento, por facilitar a difusão dos compostos extraíveis no solvente. A adição de água também intensificou a extração por alterar a polaridade do solvente. A melhor condição para a extração foi com a temperatura de $75 \stackrel{\circ}{\circ}$ e solvente com $75 \%$ de etanol em água. Os experimentos com temperatura a $100{ }^{\circ} \mathrm{C}$ obtiveram os maiores rendimentos, porém o teor de fenólicos e a capacidade antioxidante foram menores. Pode-se concluir que tenha ocorrido a degradação de compostos termossensíveis nessa temperatura.

\section{Agradecimentos}

Gostaria de agradecer aos meus orientadores Francisco Manuel Barrales e Julian Martínez por todas as instruções e orientações oferecidas durante realização do projeto, ao CNPq pela bolsa e à FAPESP (2017/23670-2) pelo auxílio financeiro. 